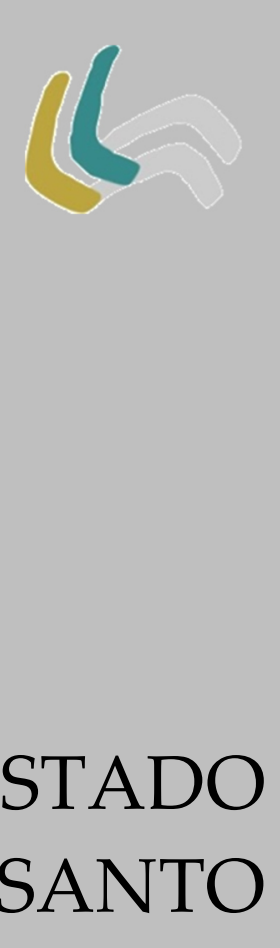

\title{
OS RÓTICOS NO ESTADO DO ESPÍRITO SANTO
}

\author{
THE RHOTICS IN THE STATE \\ OF ESPÍRITO SANTO
}

\author{
Shirley Vieira ${ }^{1}$ \\ Universidade do Estado do Rio de Janeiro
}

Resumo: Considerando a diversidade linguística acerca do rótico no Brasil, o presente artigo averigua suas variantes entre falantes do Estado do Espírito Santo. O estudo, pautado na Dialetologia e na Sociolinguística Laboviana, conta com 128 informantes, em entrevistas coletadas em 32 municípios capixabas. Os dados foram analisados utilizando o Goldvarb 2001, e representados espacialmente por meio de mapas. Como resultado, observamos em contexto final, alta taxa de apagamento da variável $(81 \%)$. Nos demais contextos, houve predominância da variante fricativa glotal [h]. Em relação à distribuição espacial das variantes, observamos áreas de diferenciação em algumas microrregiões capixabas, sobretudo em regiões de forte imigração em seu processo de colonização. Destacamos o papel da variável gênero em nossos resultados, que mostram as mulheres como propulsoras no uso das formas mais inovadoras.

Palavras-Chave: Róticos; Variação fonológica; Dialeto capixaba; Sociolinguística.

1 Endereço eletrônico: soushirley@gmail.com. 
Abstract: Considering the linguistic diversification regarding the rhotic in Brazil, this work aims to analyse its occurrence among speakers of the Espirito Santo state. The study is based on the Dialectology and the Labovian's Sociolinguistics. 128 people in 32 different municipalities of Espirito Santo were interviewed. The collected data were analysed using the Goldvarb 2001 software and was spatially represented through maps. We observed a high level of rhotic deletion in word final context. In the other cases, there was a predominance of the glottal fricative variant $[h]$. With respect to the spatial distribution of the variants, we observed areas of differentiation in some capixaba's regions, especially those with a relevant presence of immigration in their colonization process. We highlight the role of the gender variable in our results, which show that women use innovative forms than men.

Keywords: Rhotics; Phonological variation; Capixaba's dialect; Sociolinguistics.

\section{INTRODUÇÃO}

As diversas formas de realização do /r/ sempre foram temas de estudo e, no português do Brasil, podem delimitar áreas dialetais. Sabemos que o rótico apresenta vasto leque de variação: em contexto pós-vocálico, por exemplo, pode manifestar-se por uma variante vibrante, um retroflexo, um tepe, uma fricativa velar, uma aspiração, dentre outras realizações, ou até mesmo, em final de palavra, não ser pronunciado.

Malmberg (1954) registra, do ponto de vista da articulação, duas espécies de róticos: um /r/ anterior também chamado apical e um /r/ posterior ou uvular. Segundo ele, o /r/ anterior é pronunciado com a ponta da língua contra os alvéolos, empurrando a corrente de ar para frente, com várias batidas - por isso chamado de /r/ múltiplo, ou rolado. Essa é a forma primitiva desse fonema na Europa e, provavelmente, seja o /r/ indo-europeu primitivo. $\mathrm{O}$ autor observou a mudança de pronúncia do /r/ apical para uma pronúncia uvular do fone, que, segundo ele, trata-se de um fenômeno urbano que teve início nas classes superiores da sociedade.

Alguns estudos atestaram que o processo de mudança de anterior para posterior está em curso na nossa língua, em alguns dialetos (CALLOU, 1979; CALLOU; MORAES, 1995). Tais pesquisas apontam para diferenças dialetais na 
realização dos róticos, bem como fatores linguísticos e sociais que condicionam essa variação, como idade, gênero, dentre outros.

Outro fenômeno bastante comum em final de sílaba é o apagamento do rótico, chamado também de zero fonético. Autores como Alencar (2007), por exemplo, afirmam que esse fenômeno, mais especificamente, a supressão em final de palavra, estaria tradicionalmente ligado à linguagem popular, porém, observou-se tal generalização também na fala culta do Rio de Janeiro, ou seja, trata-se de um processo também observado entre pessoas com alta escolaridade. A explicação para esse fenômeno de supressão seria uma simplificação da estrutura silábica, embora haja condicionamento linguístico e extralinguístico. Um dos contextos mais frequentes de apagamento do /r/ dá-se em verbos com marca de infinitivo; quando em vocábulo com outra classe morfológica, como substantivo e adjetivo, esse apagamento mostra-se menos recorrente.

A supressão do /r/ em final de palavra pode ser associada ao fato de que em final de vocábulo ocorre, geralmente, uma aspiração (fricativa laríngea ou glotal) considerada uma consoante frouxa, sem intensidade, que propicia maior relaxamento na pronúncia. Silva (2002) reitera que o contraste fonêmico entre /r/ forte e $/ \mathrm{r} /$ fraco neutraliza-se em posição final, podendo o rótico variar consideravelmente de dialeto para dialeto.

Considerando assim tamanha variedade acerca do /r/ no Brasil, buscamos analisar a presença do rótico em posição final de vocábulo, em contexto medial, no início de palavra e em contexto intervocálico, de modo a analisar as realizações no dialeto capixaba e investigar em que estágio se encontra o fenômeno da posteriorização do rótico entre os falantes do estado do Espírito Santo. O presente estudo tende a propiciar uma análise mais sistemática dessa tendência, além de contribuir para um maior conhecimento do dialeto capixaba.

Quanto aos pressupostos teóricos, seguimos as bases teóricometodológicas da Dialetologia - estudo sistemático dos dialetos, utilizando-nos 
de cartas linguísticas, de modo a observarmos a variação dos róticos no Espírito Santo -; e da Sociolinguística - estudo da relação língua e sociedade na perspectiva laboviana da Teoria da Variação.

Com surgimento no final do século XIX, a partir da publicação do Atlas linguistique de La France, de Jules Gilliéron e Edmond Edmond, a Dialetologia pode ser definida como "ramo da Línguística que se ocupa da identificação e descrição dos diferentes usos de uma determinada língua, considerando a distribuição diatópica, os aspectos socioculturais e a cronologia dos dados" (CARDOSO, 2016, p. 13). A Geolinguística, considerada método específico da Dialetologia, fundamenta-se no tripé rede de pontos, informantes e questionário, para a produção de mapas (ou cartas linguísticas) para representação espacial da variação das formas da língua.

Outra área que também correlaciona língua e uso social é a Sociolinguística, que teve início na década de 60, principalmente a partir dos estudos de Willian Labov. No Brasil, as pesquisas no campo da Sociolinguística Laboviana resultaram em grande volume de trabalhos a respeito das muitas variedades do português brasileiro. Como dissemos, a Sociolinguística passa a considerar a língua em seu contexto social, e, a partir disso, tem como objeto de estudo a variação, que considera ser princípio geral e universal, passível de ser estudado sistematicamente. Assim, Labov, com vistas a sistematizar o estudo dessa teoria, estipula alguns pressupostos que regem a análise científica dessa nova ciência.

\section{ESTUDOS SOBRE O /r/ NO PORTUGUÊS BRASILEIRO}

O estudo do /r/ tem recebido, desde muito tempo, uma atenção especial. Isso se deve a sua vasta possibilidade articulatória, que resulta em grande variação. Callou e Moraes (1995) afirmam que, 
Por ser um fonema que - numa perspectiva funcionalista - está menos integrado ao sistema fonológico da língua, oferece uma latitude articulatória ampla, uma flexibilidade que permite seu deslocamento tanto na dimensão vertical (de vibrante a fricativa) quanto no eixo longitudinal, com uma tendência observada em quase todas as línguas, à posteriorização de seu ponto de articulação. (CALLOU; MORAES, 1995, p. 69)

Quanto a essa mudança em seu ponto de articulação, trata-se de um fenômeno já observado em diversas línguas, resultando na mudança da pronúncia de "r" anterior para posterior. Segundo as autoras, essa mudança no sentido à posteriorização do /r/ foi consolidada no dialeto parisiense, na França, resultando em uma articulação uvular, o chamado /r/ grasseyé.

A substituição de variantes apicais por vibrações uvulares e velares para a variante forte no português foi referenciada, no final do Século XIX, por Vianna, apud Callou e Leite (1994), que observa a fricatização da variável.

Outro fenômeno também bastante observado nos falares brasileiros é o apagamento do rótico em final de palavra, que seria justificado pelo fato de que em final de vocábulo ocorre, geralmente, uma aspiração (fricativa laríngea ou glotal). Trata-se de uma consoante frouxa, sem intensidade, propiciando máximo relaxamento. Desse modo, verifica-se aí, conforme Callou e Leite (1994), duas forças atuantes: uma articulatória e outra silábica, que "leva a aumentar o desequilíbrio ou assimetria que constitui uma lei fundamental da sílaba: reforço da explosão e debilitação da implosão silábica" (CALLOU; LEITE, 1994, p. 78).

Um dos estudos sociolinguísticos pioneiros em relação ao /r/ no Brasil foi o de Votre (1978). Segundo o autor, a perda do rótico em final de palavra trata-se de uma mudança que vem desde o latim, passando pelo português arcaico e, nos últimos séculos, se dissemina por todas as classes de vocábulos, na modalidade não tensa. Nesse estudo, o autor constatou baixa probabilidade de presença do rótico em final de vocábulo entre os universitários e possibilidade ainda menor 
de manutenção entre os analfabetos. $\mathrm{O}$ autor defende que o apagamento em final de vocábulo corresponde a um processo de variação estável.

Outra obra de extrema relevância nos estudos do /r/ foi a de Callou (1979). Sua tese de doutorado, seguindo os métodos quantitativos da Sociolinguística, sinalizou que houve uma mudança da pronúncia na fala urbana culta do Rio de Janeiro, mudança essa no ponto de articulação (de anterior para posterior) e no modo de articulação (de vibrante para fricativa). Seus estudos confirmam a regra de posteriorização, segundo a qual o /r/ em posição de coda silábica tende a uma pronúncia posterior e consequente enfraquecimento, que levaria à simplificação silábica do português, ou seja, seu cancelamento quando em posição final.

Outros trabalhos confirmam esses fenômenos. Em relação ao modo de articulação, Nascimento (2009) observou os róticos na fala de indivíduos de três municípios fluminenses, a saber, Petrópolis, Itaperuna e Parati. Em sua pesquisa, a autora constatou que o processo de variação e mudança dos róticos, no sentido de uma pronúncia mais posterior, continua em expansão. Observa também alto índice de presença da variante glotal, bem como do cancelamento de /r/ em final de vocábulo, que aponta forte indício de simplificação silábica no português brasileiro. Confirmam ainda esses resultados autores como Oliveira (2001), Alencar (2007) e Brandão (2008), dentre outros.

Entretanto, contrariando essa tendência, Monaretto (2009) observa um conjunto de trabalhos realizados em diversas cidades do sul do país, no qual destaca que, nas cidades do interior, o processo de posteriorização não é notado, exceto na cidade de Londrina. Isso mostra que outros fatores podem estar envolvidos nesse processo, como grupo geográfico e questões de identidade social e étnica.

A respeito da variação dos róticos em contextos pré e pós-vocálico entre os pomeranos, Bilharva da Silva (2020) investiga essa realização na fala de habitantes de São Lourenço do Sul (RS), cidade com forte influência cultural e 
linguística. Participaram dessa pesquisa dez informantes, sendo cinco bilíngues (falantes de português e pomerano) e cinco monolíngues (falantes de português, exclusivamente). Considerando um ambiente não contrastivo nos segmentos observados, o que possibilita maior liberdade articulatória, o autor propôs observar a influência do pomerano sobre o português. Como resultado, constatou que em posição pré-vocálica o tepe é a variante mais recorrente tanto entre bilíngues como entre os falantes monolíngues. Já em contexto pós-vocálico, enquanto a maioria dos monolíngues utiliza o tepe, os falantes bilíngues utilizam diferentes realizações do rótico, como vibrantes múltiplas, aproximantes e fricativas palato-alveolares desvozeadas. Bilharva da Silva (2020) conclui que, principalmente em contexto pós-vocálico, os resultados foram influenciados pelo pomerano, já que nesse contexto não se verifica a produção de tepe na citada língua.

Ainda a propósito das diversas pesquisas sobre os róticos realizados no sul do país, Leal (2016) propôs uma generalização dos resultados obtidos em alguns trabalhos ao longo dos últimos anos nessa região, em uma análise metodológica do tipo abrangente. Em relação ao apagamento do rótico, a autora observou que, de modo geral, o rótico é categoricamente preservado em posição de ataque. No que tange à posição final de sílaba, temos que em coda medial, no interior da palavra, o apagamento do rótico é geralmente desfavorecido em cidades dos três estados sulistas. Em relação ao /r/ em coda final de nomes, a autora observa nas pesquisas que também existe tendência à permanência do rótico nessa posição. Por outro lado, em coda final de verbos, observa-se uma tendência geral ao apagamento de /r/, com exceção de Monaretto (2002), que, analisando dados do projeto NURC, observa permanência de rótico em várias cidades do Sul.

Destarte, observando que o fator localidade também se mostra relevante no processo de posteriorização e apagamento do rótico, bem como na variação 
de outros fenômenos, julgamos pertinente o exame do /r/ no Espírito Santo, com vistas a inserir tal estado no rol das pesquisas linguísticas da vibrante.

\section{METODOLOGIA}

Os dados analisados neste artigo foram captados a partir de entrevistas exclusivas realizadas entre os anos de 2014 e 2016 para um trabalho mais geral de análise do /r/ no estado do Espírito Santo (VIEIRA, 2017). O trabalho citado refere-se à tese de doutorado que objetivou a análise do comportamento dos róticos no referido estado, observando a ocorrência das variantes do $/ \mathrm{r} /$ nos diversos contextos silábicos, bem como a observação do já conhecido processo de mudança no ponto de articulação do rótico, de anterior para posterior.

Para isso, percorreu-se um total de 32 municípios do estado em questão, sendo que em cada um deles foram entrevistados quatro informantes: dois homens e duas mulheres, distribuídos em duas faixas etárias, de 18 a 30 anos e de 50 a 65 anos, totalizando 128 informantes. Para elaboração do questionário e coleta de dados, nos pautamos nos critérios utilizados pelo Atlas Linguístico do Brasil (ALiB), assim, todos os informantes são nascidos nos municípios visitados e têm como escolaridade o ensino fundamental.

As questões do questionário aplicado foram adaptadas do questionário fonético-fonológico do ALiB. As entrevistas tiveram média de duração de 22 minutos, incluindo perguntas objetivas e conversa informal. Para nosso trabalho, porém, utilizamos somente dados das questões objetivas, visto a impossibilidade de tratamento do material em curto período de tempo.

Para esta abordagem, como já citado, dividimos as ocorrências em quatro contextos de realização: contextos pós-vocálico final, pós-vocálico medial, pré-vocálico inicial e intervocálico. Os vocábulos resultantes do inquérito que visam ao estudo do rótico em nosso trabalho são os seguintes: mar, varrer, colher (subst.), 
liquidificador, botar/colocar, montar, calor, trabalhar, rasgar, pintor, beijar, computador, achar, perguntar, sair, revólver, vomitar, calcanhar, bar, perder, mentir.

Como variáveis linguísticas, analisamos aqui a dimensão do vocábulo, classe morfológica, natureza do contexto fonológico precedente e natureza do contexto fonológico seguinte. Em relação às variáveis extralinguísticas, averiguamos a localidade, o gênero e a faixa etária dos informantes. Observamos que, para seleção das localidades, levamos em conta a divisão política do estado do Espírito Santo, que consiste em dez microrregiões.

Após coleta, transcrição e decodificação dos dados, utilizamos o pacote de programas Varbrul, mais especificamente, a versão Goldvarb 2001. Esse instrumento, muito utilizado nas pesquisas sociolinguísticas, auxilia no manejo de cálculos matemáticos e estatísticos, permitindo calcular a probabilidade de cada fator em relação à variável dependente considerada (GUY; ZILLES, 2007).

Ressaltamos que a versão do Varbrul aqui utilizada realiza apenas rodadas binárias. Assim, é preciso reduzir as variáveis dependentes a dois fatores para prosseguirmos com os testes com intuito de gerar os pesos relativos. O peso relativo é o produto final para cada um dos fatores examinados. Segundo Brescancini (2002), considerando que a variável dependente está inserida em um contexto linguístico e social e estes podem influenciar na escolha do falante, o programa gera, através de cálculos, percentagens para cada um dos fatores quando se chega ao peso relativo que reflete as várias interferências na regra.

É importante salientar que tal pacote de programas consiste num valioso instrumento de apoio para a análise variacionista. Contudo, esses dados isoladamente não dão conta de uma análise tão complexa. Assim, esses resultados devem ser analisados à luz da Teoria da Variação, sendo observados os fatores sociais e linguísticos, bem como a realidade da comunidade em estudo.

Esclarecemos que o processo de transcrição dos dados foi baseado na impressão auditiva do material coletado. Utilizamos como referência o Alfabeto 
Fonético Internacional (IPA). Observamos que os dados não foram submetidos a uma análise em laboratório, metodologia que pode ser acrescentada em trabalhos posteriores.

\section{ANÁLISE: O COMPORTAMENTO DO /r/ NO ESPÍRITO SANTO}

\section{1 $\mathrm{O} / \mathrm{r} / \mathrm{em}$ contexto final de vocábulo}

A posição final de vocábulo foi um dos contextos de /r/ observado em nossa pesquisa. Nessa circunstância, podemos presenciar uma gama de variações do rótico, que pode se realizar pela pronúncia fricativa velar ou aspirada, retroflexa, tepe, e ainda o zero fonético, fenômeno cada vez mais recorrente no Brasil.

Após a inserção dos dados no programa Goldvarb 2001, obtivemos a realização geral das variantes estudadas. Observamos que o zero fonético teve maior realização dentre as variantes analisadas. Foram contabilizados 2.713 dados para a análise do /r/ em posição final de vocábulo. Desse total, presenciamos 2.202 ocorrências de apagamento (81\%), 406 de fricativa glotal (15\%), 68 de fricativa velar (3\%), 31 de tepe (1\%), e ainda 06 ocorrências da variante retroflexa, que teve percentual irrelevante estatisticamente.

Conforme diversos estudos acerca do /r/ em posição final de vocábulo, como em Oliveira (2001) e Callou (1979), os resultados de nossa análise também mostram a variante apagamento com alto índice de ocorrência. Alguns desses estudos já evidenciaram que o /r/ pós-vocálico é apagado com mais recorrência em determinadas condições, como em verbos no infinitivo e em substantivos com maior extensão de sílabas.

Neste trabalho, o grupo de fatores mais relevante foi a dimensão do vocábulo. Essa variável foi selecionada como a mais relevante para a supressão do rótico, 
com peso relativo de 0.67 para os vocábulos polissílabos, seguida pelos trissílabos, com 0.62, como podemos observar na Tabela 1.

Tabela 1: Apagamento/r/ pós-vocálico - variável dimensão do vocábulo

\begin{tabular}{c|c|c|c|c|c|c} 
& \multicolumn{3}{|c|}{ Apagamento } & \multicolumn{2}{c}{ Manutenção " $\mathrm{r}^{\text {" }}$} & Total \\
\hline Fatores & № & $\%$ & $\begin{array}{c}\text { Peso } \\
\text { relativo }\end{array}$ & № & $\%$ & \\
\hline Polissílabos & 206 & 79 & .67 & 52 & 21 & 258 \\
\hline Trissílabos & 592 & 89 & .62 & 71 & 11 & 663 \\
\hline Dissílabos & 1.272 & 85 & .54 & 220 & 15 & 1.492 \\
\hline Monossílabos & 132 & 44 & .15 & 168 & 56 & 300 \\
\hline Total & 2.202 & \multicolumn{7}{|c|}{} & 511 & & 2.713 \\
\hline
\end{tabular}

Fonte: Vieira (2017).

Esses resultados ratificam a proposição de que quanto menor a palavra, maior a chance de manutenção de /r/ e vice-versa, visto a baixa ocorrência de aplicação da regra entre os monossílabos, com peso de 0.15 . Os resultados em questão corroboram as pesquisas de autores como Callou, Moraes e Leite (2002), que observaram maior índice de apagamento em palavras polissílabas. Devemos reconhecer que, em nosso corpus, o índice de vocábulos com função de verbos infinitivos é bastante alto, se comparado aos substantivos. No entanto, mesmo perante essa condição, o apagamento em palavras não verbais com maior número de sílabas ainda foi significativo. Em trabalho mais extenso, optamos por realizar uma rodada estatística dessa variável exclusivamente entre os substantivos:

Tabela 2: Apagamento " $\mathrm{r}$ " pós-vocálico - dimensão do vocábulo entre substantivos

\begin{tabular}{c|c|c|c|c|c} 
& \multicolumn{2}{|c|}{ Apagamento } & \multicolumn{2}{c|}{ Manutenção } & \multirow{2}{*}{ Total } \\
\cline { 2 - 5 } & № & $\%$ & № & $\%$ & \\
\hline Monossílabos & 88 & 35 & 163 & 65 & 251 \\
\hline Dissílabos & 273 & 72 & 110 & 28 & 383 \\
\hline Trissílabos & 206 & 88 & 27 & 12 & 233 \\
\hline Polissílabos & 204 & 80 & 52 & 20 & 256 \\
\hline Total & 771 & & 352 & & 1.123 \\
\hline
\end{tabular}

Fonte: Vieira (2017). 
Conforme esperávamos, apoiados em resultados de diversos trabalhos, também entre os substantivos o apagamento é predominante, exceto entre os monossílabos, que em nossos dados correspondem aos vocábulos mar e bar, que condicionam a manutenção do rótico em final de palavra.

Outro grupo de fatores selecionado pelo programa para a regra de apagamento de /r/ em final de vocábulo foi a localidade. Os números apresentados mostram que, apesar da pequena extensão territorial do estado, as microrregiões que o compõem apontam resultados diferenciados quanto à regra de apagamento do /r/ em final de palavra. O Mapa 1 a seguir ilustra tal ocorrência. Verificamos que em quase toda a faixa litorânea ocorre essa regra. Já as regiões mais ao sudoeste do estado, apesar de apresentarem altos índices percentuais, mostram-se desfavoráveis à supressão de /r/ em contexto final. Para demarcação espacial dos mapas aqui representados, consideramos os resultados do Goldvarb 2001, que, de acordo com Guy e Zilles (2007), indicam em termos de peso relativo que os números acima de 0,50 representam o favorecimento da regra, nesse caso, o apagamento do /r/; os com peso 0,50 podem ser considerados neutros e, por fim, a taxa abaixo de 0,50 demonstra desfavorecimento da variante em questão, ou seja, a manutenção do rótico.

Destacamos que, quando o /r/ se manifesta, os menores índices da fricativa glotal (segunda maior ocorrência entre os dados) estão nas microrregiões serranas (Central Serrana com 12 casos e Sudoeste Serrana com 8 casos), além da região Metropolitana. Nas regiões serranas também encontramos a maioria dos casos da variante tepe. Esse fenômeno pouco comum nas demais microrregiões do estado pode estar associado à colonização dessas áreas por imigrantes alemães, pomeranos e italianos, que, em muitos casos, têm outras línguas/dialetos como primeira língua. Essa variação influenciada pelas línguas de imigração pode ser observada em trabalhos como o de Bilharva da Silva (2020), Schaeffer (2012) e Benincá (2008). 
Mapa 1: Apagamento de /r/ em contexto final de vocábulo

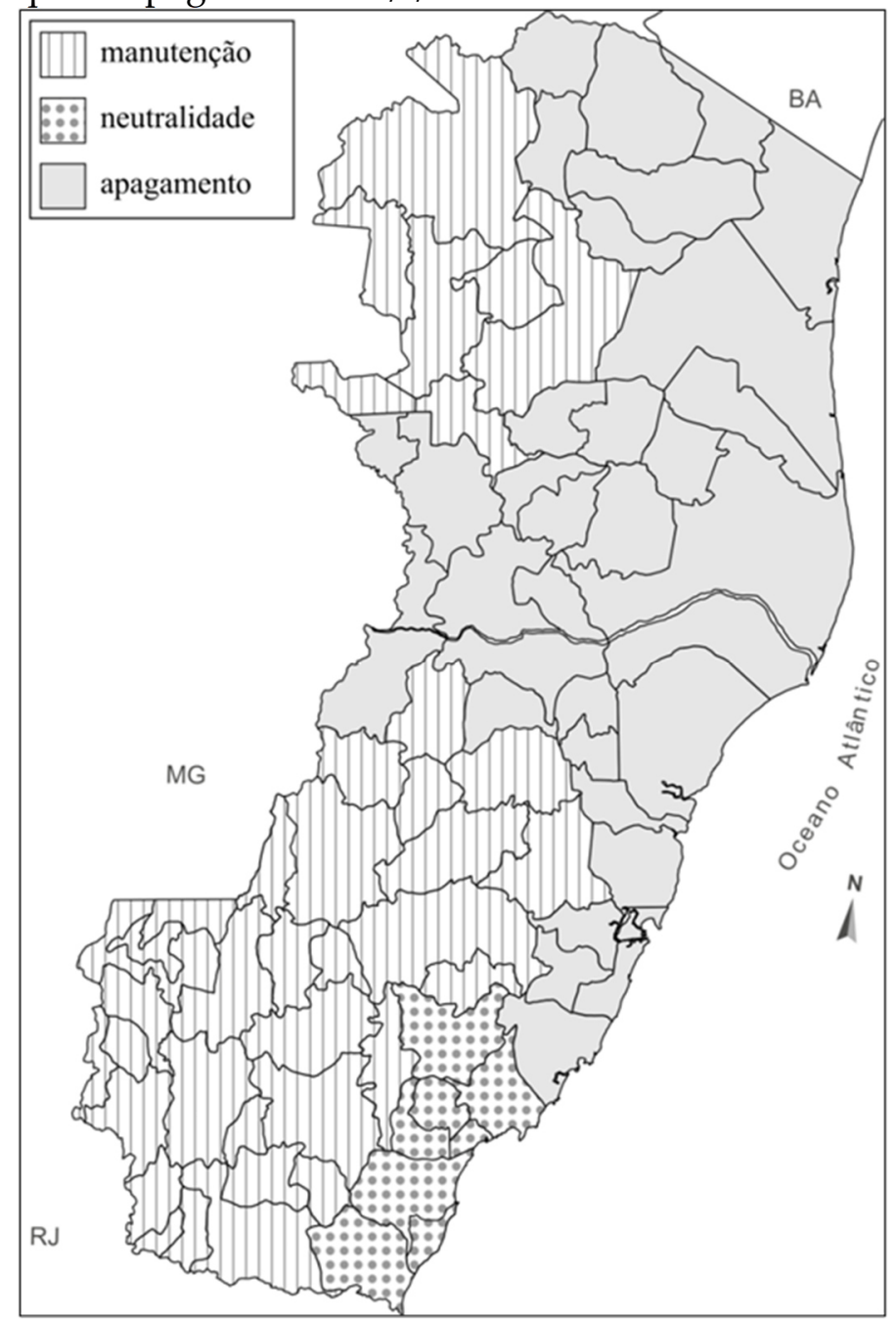

Fonte: Vieira (2017).

Na sequência da análise do /r/ em final de vocábulos, as demais variáveis analisadas apresentaram os seguintes resultados: em relação ao contexto fonológico seguinte, os contextos não pausados, ou seja, quando há continuidade de fala por parte do informante após a pronúncia da palavra desejada foram os mais relevantes para o apagamento. Quanto ao contexto precedente, as palavras que apresentaram vogal anterior $[\mathrm{i}, \mathrm{e}, \mathrm{o}]$ foram as mais suscetíveis à queda do $/ \mathrm{r} /$ final. Já a variável classe morfológica, apesar de não ter sido a primeira selecionada pelo programa, apresenta grande destaque, visto que os verbos 
foram preponderantes para a regra de apagamento, como destacado em diversos estudos ${ }^{2}$.

Vale ressaltar que em diversos trabalhos, como o de Votre (1978), comprovou-se o apagamento do /r/ final, sobretudo, em verbos. Em nossa pesquisa, essa tendência também se confirma, ou seja, os verbos apresentaram alto índice de supressão, mesmo aqueles compostos de uma única sílaba. Cabe grifar que em nosso corpus o número de vocábulos com verbos apresenta-se muito superior em relação ao de outras classes gramaticais, contabilizando 1.431 palavras, enquanto as demais somam 771. Todavia, acreditamos que essa desproporção não tenha influenciado nos resultados obtidos, tendo em vista a metodologia do programa estatístico ao qual os dados foram submetidos.

Nesse ponto torna-se imprescindível salientarmos que, quando pronunciado, $\mathrm{o} / \mathrm{r} /$ se manifesta por sua variante fricativa glotal, que trata de uma versão mais enfraquecida da vibrante, que seria o processo anterior a seu apagamento. Callou e Leite (1994) apontam que, nessa posição, no dialeto do Rio de Janeiro, a consoante mostra-se débil e sua ausência é muitas vezes compensada pelo prolongamento da vogal precedente. Ainda, segundo alguns autores, como Callou, Moraes e Leite (2002), o rótico em posição de coda passa por um processo de enfraquecimento em direção ao desaparecimento, nesta sequência: $\mathrm{r} \rightarrow \mathrm{R} \rightarrow \chi \rightarrow \mathrm{h} \rightarrow \varnothing$.

Por fim, considerando ainda o contexto final, observamos um percentual de $19 \%$ das variantes fricativas e tepe, quando na pronúncia do rótico nesse contexto. Dentre as ocorrências de /r/ em contexto final de vocábulo, verificamos trinta e sete variantes dentre tepes e retroflexas na fala dos informantes mais velhos, e somente duas ocorrências na fala dos mais jovens, ratificando a mudança no ponto de articulação - de anterior para posterior - também no dialeto capixaba.

2 Mais detalhes em Vieira (2017). 


\section{2 $\mathrm{O} / \mathrm{r} / \mathrm{em}$ contexto pós-vocálico medial}

Diversos autores já realizaram estudos sobre o /r/ em contexto medial, como Alencar (2007), Skeete (1997), Callou (1979), Callou e Moraes (1995), Brandão (2008), Nascimento (2009), dentre outros. Nesse contexto, consideramos as seguintes variantes do rótico: o tepe, a fricativa velar, o retroflexo, a fricativa glotal e o apagamento $[\mathrm{r}, \chi, \mathrm{c}, \mathrm{h}, \varnothing]$.

Submetidos os dados ao Goldvarb 2001, observamos, em contexto medial, maior ocorrência da variante glotal, com percentual de 54\% (1.665 dados). Em seguida, percebemos a presença da variante velar, com 22\% (681). A taxa de apagamento, por sua vez, obteve percentual de 14\% (445). As ocorrências de tepe e retroflexa ficaram em 06\% (201) e 02\% (64), respectivamente, totalizando 3.056 dados.

Autores como Callou e Moraes (1995) já apontavam indícios de oposição entre norte e sul do Brasil em relação ao rótico nessa posição. Nas capitais mais ao norte (Rio de Janeiro, Salvador e Recife) há taxas mais elevadas de aspiração. Por outro lado, mais ao sul (São Paulo e Porto Alegre) essas taxas são mais modestas, dando prioridade ao tepe. Também na região nordeste, para Alencar (2007), a variante glotal mostrou-se mais recorrente em contexto medial, alcançando taxa de $90 \%$ da variante aspirada e 10\% de apagamento.

Em nossa pesquisa, após as rodadas, o programa selecionou como relevantes os seguintes grupos de fatores: gênero, classe morfológica, contexto antecedente, faixa etária, localidade, contexto seguinte e tonicidade. Quanto à variável gênero, observamos que as mulheres pronunciam com muito mais recorrência a variante fricativa glotal (67\%), enquanto entre os homens o percentual é de $41 \%$. O índice de apagamento é o mesmo entre homens e mulheres, 15\%. 
Os resultados apontam, como em trabalhos já citados, que há um forte indicativo de inovação na língua a partir da fala das mulheres. Para Callou (1979), a mudança no ponto e modo de articulação do rótico tem maior probabilidade de ocorrência entre o público feminino. No caso do /r/, podemos verificar que a variante inovadora é a fricativa glotal.

Outra variável social relevante para o uso da aspirada em contexto medial de palavra foi a idade. Entre os mais jovens (faixa 1), o peso relativo foi de 0.57 , apontando maior probabilidade de pronúncia dessa variante:

Tabela 3: Contexto medial - variável faixa etária

\begin{tabular}{c|c|c|c|c|c|c} 
& \multicolumn{3}{|c|}{ Fricativa glotal } & Demais variantes & \multirow{2}{*}{ Total } \\
\cline { 1 - 5 } Faixa etária & № & $\%$ & $\begin{array}{c}\text { Peso } \\
\text { relativo }\end{array}$ & № & $\%$ & \\
\hline Faixa 1 & 915 & 60 & .57 & 595 & 40 & 1.510 \\
\hline Faixa 2 & 750 & 48 & .42 & 796 & 52 & 1.546 \\
\hline Total & 1.665 & & & 1.391 & & 3.056 \\
\hline
\end{tabular}

Fonte: Vieira (2017).

Como visto em outros trabalhos, os mais jovens utilizam mais a variante aspirada que os mais velhos, fator que vislumbra uma possível mudança no padrão linguístico. Sabemos que tanto a variável gênero como a faixa etária costumam se mostrar bastante relevantes nos resultados de muitas pesquisas sociolinguísticas. Nesse sentido, considerando a pertinência dessas variáveis sociais, achamos conveniente amalgamarmos esses dois grupos:

Tabela 4: Contexto medial - cruzamento variáveis gênero $\mathrm{x}$ faixa etária

\begin{tabular}{|c|c|c|c|c|c|c|c|}
\hline & \multicolumn{3}{|c|}{ Fricativa glotal } & \multicolumn{2}{|c|}{ Demais variantes } & \multirow[b]{2}{*}{ Total } \\
\hline & & № & $\%$ & $\begin{array}{c}\text { Peso } \\
\text { relativo }\end{array}$ & № & $\%$ & \\
\hline \multirow{2}{*}{ Feminino } & Faixa 1 & 542 & 70 & .66 & 224 & 30 & 766 \\
\hline & Faixa 2 & 497 & 65 & .59 & 279 & 35 & 776 \\
\hline \multirow{2}{*}{ Masculino } & Faixa 1 & 373 & 51 & .45 & 371 & 49 & 744 \\
\hline & Faixa 2 & 253 & 33 & .28 & 517 & 67 & 770 \\
\hline & Total & 1.665 & & & 1.391 & & 3.056 \\
\hline
\end{tabular}

Fonte: Vieira (2017). 
Observando que a variante glotal pode ser, nesse contexto, considerada a mais inovadora, os dados condizem com outros trabalhos (NASCIMENTO, 2009). Em nossos resultados, além da variável gênero, que mostra as mulheres em vantagem na utilização da fricativa glotal, também o fator faixa etária foi considerado relevante para a regra de aspiração. Assim, podemos deduzir que são realmente as mulheres mais jovens que lideram esse processo.

Em relação à variável localidade, constatamos que a pronúncia glotal em contexto medial de palavra ocorre nas regiões mais litorâneas do estado, enquanto as demais variantes, embora em números atenuados, ocupam a parte interiorana capixaba, como observado no Mapa 2.

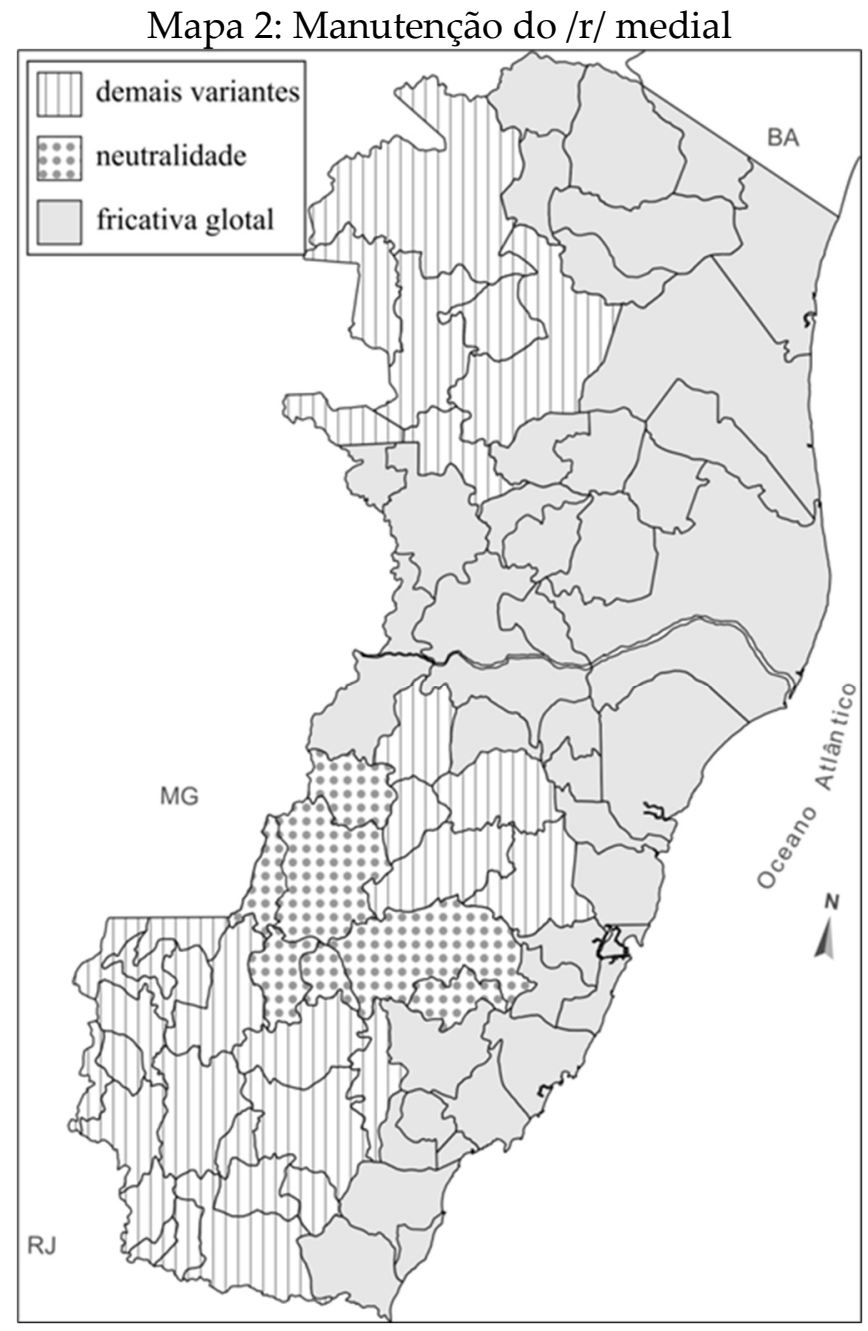

Fonte: Vieira (2017). 
Finalmente, foi selecionado pelo programa o contexto seguinte e a tonicidade. No contexto seguinte, as consoantes nasais e africadas condicionaram a pronúncia glotal no contexto analisado. Em relação ao fator tonicidade, as sílabas átonas influenciaram a versão mais enfraquecida do rótico, ou seja, a fricativa glotal.

Em nosso corpus, como já mencionado, averiguamos 441 ocorrências da variante zero nesse contexto. Devemos enfatizar que algumas palavras estão mais condicionadas ao apagamento que outras. As palavras catorze e perfume, recorrentes vezes são pronunciadas catozi e pefumi.

Quanto à ocorrência das variantes anteriores, em termos numéricos, as variantes com esse traço [+ant], a saber, o tepe, o retroflexo e a vibrante, somaram 310 ocorrências, sendo essas principalmente em posição de coda final e medial. Nesse contexto, foram encontrados 265 dados em posição medial de palavra, distribuídos entre as variantes tepe (201 casos) e retroflexo (64 dados).

Analisando as variáveis favoráveis a essa ocorrência, devemos observar o fator gênero. Em relação aos homens, contabilizamos 175 casos de variantes anteriores (tepe e retroflexo); já entre as mulheres, essas variantes se repetem 90 vezes, ou seja, quase metade do total realizado por falantes do sexo masculino. Paiva (2008) afirma que, não raro, as mulheres tendem a liderar processos de mudança linguística, estando, comumente, uma geração à frente dos homens. Apesar disso, não podemos confirmar que são elas as responsáveis pelas mudanças na língua. O que se observa entre o sexo feminino, segundo a autora, seria uma maior sensibilidade entre as mulheres quanto às formas de prestígio social atribuído às variantes.

É certo que num processo de mudança linguística um aspecto a ser considerado é o valor social da variante inovadora. No caso do uso das variantes [+ant], trata-se de um processo que há muito vem sendo observado, que seria a 
mudança para uma pronúncia posterior. Diversos trabalhos, como o de Callou (1979), apontam as mulheres como líderes no uso da regra de posteriorização. Nesse sentido, os resultados de nossa pesquisa condizem com o comumente observado nas demais comunidades linguísticas.

Em relação à faixa etária, percebemos um percentual bem mais alto na primeira faixa (18 a 30 anos), em relação à variante fricativa glotal (61\% entre as mulheres e $49 \%$ entre os homens) e à fricativa velar (24\% para as mulheres e $20 \%$ entre os homens). Os índices de retroflexo e tepe mostraram-se mais relevantes entre os mais velhos (50 a 65 anos), com 4\% e 12\%, respectivamente. Quanto ao apagamento em contexto medial, ambas as faixas tiveram percentuais similares (em torno de $15 \%$ ).

A partir dos dados expostos, fica nítido que as variantes posteriores, no caso, as fricativas velar e glotal, são bem mais recorrentes na faixa etária 1, entre os mais novos, atingindo cerca de $85 \%$ dos casos. Entre os mais velhos, esse índice cai para $69 \%$, o que confirma o já avançado estágio de posteriorização de /r/ no estado do Espírito Santo.

Destarte, é através da variável idade que se percebe o uso diferenciado das variantes, o que aponta indícios de mudança. Assim, como não se percebe o uso constante de variantes [+ant] na fala dos mais jovens, é possível deduzir a mudança do padrão em direção à posteriorização de /r/, mudança essa, aliás, tida como universal e já presenciada em diversas línguas, como no francês, no alemão, no holandês (MALMBERG, 1954).

De acordo com Chambers e Trudgill (1982), se a variante linguística se realiza predominantemente entre os mais velhos e tem baixa produtividade entre os mais jovens, pode indicar que esta se encontra em vias de desaparecimento. Caso o quadro seja inverso, indicaria um fenômeno em ascensão. Em nossa pesquisa, observamos, nesse contexto, 240 realizações [+ant] entre os informantes mais velhos e somente 25 entre os mais novos. Isso aponta que o estado do 
Espírito Santo, assim como diversas outras regiões brasileiras acompanha o já avançado processo de posteriorização do rótico. Podemos dizer que as variantes com traços mais anteriores possivelmente desaparecerão do dialeto capixaba, visto a baixa produtividade entre os falantes mais jovens, incumbidos de propagar a língua para a próxima geração.

\section{3 $\mathrm{O} / \mathrm{r} / \mathrm{em}$ contexto inicial de palavra}

Em posição pré-vocálica, ocorre somente $\mathrm{o} / \mathrm{r} /$ forte $^{3}$, independente da variante. Nessa posição, o leque de variação não é muito extenso e, por esse motivo, as pesquisas que envolvem esse contexto não são tão expressivas. Hora e Monaretto (2003) afirmam que há muitas evidências fonológicas que indicam que a posição em início de palavra é universalmente mais forte, desse modo, as consoantes iniciais seriam, inevitavelmente, mais resistentes nesse contexto.

Em nossa análise consideramos, em princípio, as seguintes variantes de /r/ em contexto inicial de vocábulo: fricativa velar $[\chi]$, fricativa glotal $[\mathrm{h}]$, vibrante múltipla [r], tepe [r] e variante retroflexa [r]. Assim, após a rodada dos dados (que totalizaram 1.372 ocorrências), observamos maior incidência da variante fricativa glotal, com 90\% dos casos (1.228 dados), seguida pela variante fricativa velar, com $10 \%$ das ocorrências (138 dados). As demais variantes não se mostraram significativas, sendo 03 casos de tepe, 03 de vibrante múltipla e nenhum caso de retroflexa - que resultaram em nocautes ${ }^{4}$.

\footnotetext{
3 De acordo com Silva (2002), o /r/ forte pode ocorrer em posição intervocálica (carro); em início de palavra (rua); e em início de sílaba precedido por consoante (Israel). Segundo a autora, o /r/ forte pode manifestar-se como fricativa ou vibrante múltipla, conforme o dialeto.

4 No programa Goldvarb 2001, um nocaute acontece quando a ocorrência de uma variável dependente resulta em $0 \%$ ou $100 \%$, não havendo assim variação (GUY; ZILLES, 2007).
} 
Em contexto inicial, foram considerados relevantes para a presença da fricativa glotal as seguintes variáveis, por ordem, o gênero, a dimensão do vocábulo, a microrregião, a faixa etária e o contexto fonológico seguinte.

Monaretto (1997) verificou, tanto em início de palavra como em início de sílaba, maior ocorrência de consoante posterior, com cerca de $69 \%$ dos casos. Em nossos dados operou-se maciçamente os casos de fricativas (glotal e velar), ou seja, de realização posterior, corroborando a tese de Monaretto.

Apesar dos números amplamente favoráveis ao uso da variante fricativa glotal, destacamos, aqui, a variável gênero, a primeira selecionada pelo programa estatístico, como podemos observar a seguir:

Tabela 5: Contexto inicial - variável gênero

\begin{tabular}{c|c|c|c|c|c|c} 
& \multicolumn{3}{|c|}{ Fricativa glotal } & \multicolumn{2}{c|}{ Fricativa velar } & \multirow{2}{*}{ Total } \\
\hline Gênero & № & $\%$ & $\begin{array}{c}\text { Peso } \\
\text { relativo }\end{array}$ & № & $\%$ & \\
\hline Feminino & 649 & 96 & .67 & 30 & 4 & 679 \\
\hline Masculino & 579 & 85 & .33 & 108 & 15 & 687 \\
\hline Total & 1.228 & \multicolumn{2}{|l|}{} & 138 & & 1.366 \\
\hline
\end{tabular}

Fonte: Vieira (2017).

Obtivemos entre as mulheres peso relativo de 0.67 e 0.33 entre os homens apontando menor propensão desses quanto ao uso da variante aspirada. Novamente devemos ressaltar o papel das mulheres na transmissão da mudança linguística. Nesse sentido, nossos resultados confirmam essa hipótese, já que são as mulheres que utilizam mais a variante considerada mais inovadora, no caso, a fricativa aspirada. Os homens, por sua vez, apesar de também utilizarem mais tal variante, utilizam com mais frequência que as mulheres a variante fricativa velar. 


\section{4 $\mathrm{O} / \mathrm{r} / \mathrm{em}$ contexto intervocálico}

A posição intervocálica é o contexto em que há oposição fonológica, causando, inclusive, diferença de sentido na palavra, como em careta: carreta; caro: carro, dentre outras. Seara (2008) destaca que no português brasileiro apenas dois sons de /r/ são distintivos, /r/ fraco e /r/ forte. A autora exemplifica que caso a

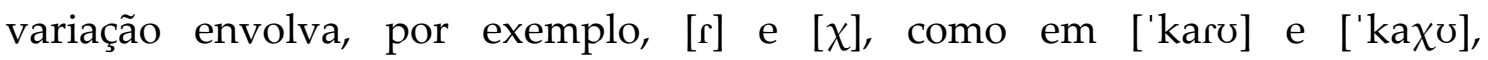
respectivamente, esses podem ser considerados pares mínimos, já que essa troca incide em alteração de sentido entre as palavras. Entretanto, caso envolva as variantes $[\mathrm{r}, \chi, \mathrm{h}]$, observaremos um caso de alofonia, já que os sons não trazem mudança de significado, como em mar ['mar], ['ma ], ['mah].

Para essa averiguação em nossa pesquisa, analisamos os seguintes vocábulos: terreno, ferro elétrico, varrer, arroz, borracha, correio, sorriso, morreu, carroça (charrete), burro, socorro e beterraba. Observamos que, em nossos dados, não temos pares em oposição fonológica.

Expomos que as variantes encontradas nesse contexto, em nosso corpus, foram a fricativa glotal, a fricativa velar e o tepe, em menor quantidade. Foram analisados nesse contexto 1.489 dados. Desse total, a variante fricativa glotal foi predominante, com 1.260 dados (85\%); a fricativa velar segue com 227 ocorrências (15\%) e o tepe com apenas 02 casos. Nenhuma outra variante foi encontrada em nosso corpus. Assim, as rodadas no programa Goldvarb foram realizadas somente com fricativas glotais e velares, totalizando 1.487 dados.

Foram selecionados como relevantes para a realização da fricativa glotal as seguintes variáveis: gênero, tonicidade, localidade, faixa etária, contexto precedente e contexto seguinte. Em relação à primeira variável, observamos grande diferença entre o uso da variante aspirada por mulheres e homens.

Considerando o princípio de que as mulheres são, em geral, inovadoras na pronúncia de determinadas formas, esses resultados condizem com a 
realidade, já que a variante glotal estaria em último estágio de mudança na direção do enfraquecimento do rótico. Os homens, mais conservadores, utilizam com maior frequência a fricativa velar.

A variável localidade também foi selecionada pelo programa estatístico, apontando maior frequência de realização da fricativa glotal na região noroeste, parte da área litorânea, na região serrana e no sul do estado. A região metropolitana, apesar de maior uso da variante glotal, também consta de índices razoáveis da fricativa velar.

Por fim, em relação aos dois casos de tepe presentes nesse contexto, que poderiam gerar contraste fonêmico, observamos que essa variante se deu no vocábulo morreu, fenômeno que Seara (2008) caracteriza como variação livre, não causando assim ambiguidade de sentidos na pronúncia de uma ou outra variante. Destacamos que os informantes que manifestaram tal realização pertencem ao sexo masculino e à segunda faixa etária, acima de 50 anos. Apesar dessas ocorrências, é preciso enfatizar que os dados revelados de tepe não se mostraram relevantes, não sendo esse o padrão, ao menos na comunidade geral do Espírito Santo.

\section{CONSIDERAÇÕES FINAIS}

A partir da análise feita acerca do $/ \mathrm{r} /$ em contexto final de vocábulo, observamos predominância da variante apagamento, seguindo uma tendência no português brasileiro, sobretudo em verbos no infinitivo. Dentre os casos de ocorrência de /r/ em final de vocábulo, embora em menor proporção, a variante fricativa glotal apresenta-se em maior número, em conformidade com a obra de Callou e Moraes (1995), que observam índice mais alto dessa variante nas cidades mais ao norte do país. 
Em relação a sua manutenção, as variantes de $/ r$ / forte, no caso, as fricativas glotal e velar são predominantes. Para a variante de maior peso, a fricativa glotal, os grupos de fatores que se mostraram relevantes foram a localidade, o contexto seguinte e a faixa etária.

Quanto ao apagamento de /r/, variante de maior recorrência, as variáveis selecionadas pelo programa foram a dimensão do vocábulo, o contexto seguinte, a vogal precedente, a classe morfológica e a localidade.

O mapa exposto a partir dos dados obtidos (Mapa 1) mostra que as áreas de apagamento do /r/ ficam mais na área litorânea do Estado capixaba, e se estendem em direção nordeste, que se limita com o estado de Minas Gerais.

Em contexto medial de vocábulo, constatamos que a fricativa glotal é a variante padrão nesse contexto, no estado capixaba. Observamos que são as mulheres e os mais jovens que lideram o uso desse padrão.

Em posição inicial de vocábulo, podemos notar que o processo de posteriorização do rótico já se encontra consolidado, visto o número irrelevante de variantes anteriores. Podemos ainda sugerir que o padrão de pronúncia no Espírito Santo caminha em direção ao completo enfraquecimento do rótico, representado pelo uso da fricativa glotal. Isso pode ser observado pelo uso menos abundante da fricativa velar, pronunciada mais frequentemente por informantes mais velhos e com menos intensidade pelos jovens, o que pode sugerir o desaparecimento da variante nesse contexto, em solo capixaba.

Por fim, em contexto intervocálico, as variantes predominantes foram a fricativas glotal, com $85 \%$, e a fricativa velar, que somou $15 \%$ de ocorrência. Os dois casos de tepe não alcançaram percentual significativo.

Enfim, convergindo com a tendência universal, observada por autores como Callou (1979) e Malmberg (1954), referente à mudança no ponto de articulação, ou seja, de anterior para posterior, nossos dados apontam que o estado do Espírito Santo encontra-se em avançado estágio de mudança, com a 
presença em maior número das fricativas glotal e velar. Essa mudança é ratificada se observarmos a variável faixa etária, na qual constata-se que as variantes com traço [+ant], ou seja, o tepe e o retroflexo, ocorrem com maior índice entre os mais velhos (35 ocorrências) quando comparadas aos falantes jovens (02 ocorrências).

Também podemos confirmar nesta pesquisa o crescente processo de apagamento de $/ \mathrm{r}$ / em contexto final de vocábulo, sendo o zero fonético a variante predominante, com $81 \%$. Esse fato caminha em direção à simplificação silábica constatada na literatura e confirmada a partir de nossos dados.

\section{REFERÊNCIAS}

ALENCAR, M. S. M. de. Aspectos sócio-dialetais da língua falada em Fortaleza: as realizações dos fonemas $/ r / \mathrm{e} / \mathrm{r} /$. 2007. 184f. Tese (Doutorado em Linguística). Universidade Federal do Ceará, Fortaleza, 2007.

BENINCÁ, L. Dificuldades no domínio de fonemas do português por crianças bilíngues de português e pomerano. Dissertação (Mestrado em Letras). Universidade Federal do Espírito Santo, 2008.

BILHARVA DA SILVA, F. Produção dos róticos em sequências consonantais [CR] e [RC] no português de contato com o pomerano. Revista A Cor das Letras. Feira de Santana, v. 21, n. 1, p. 132-154, janeiro-abril de 2020.

BRANDÃO, S. F. Variação em coda silábica na fala popular fluminense. Revista da ABRALIN, v. 7, n. 1, p. 177-189, 2008.

BRESCANCINI, C. A análise de regra variável e o programa Varbrul 2S. In: BISOL, L.; BRESCANCINI, C. Fonologia e variação: recortes do Português Brasileiro. Porto Alegre: EDIPUCRS, 2002.

CALLOU, D. M. I. Variação e distribuição da vibrante na fala culta do Rio de Janeiro. 1979. 199f. Tese (Doutorado em Língua Portuguesa). Universidade Federal do Rio de Janeiro, Rio de Janeiro, 1979.

CALLOU, D.; LEITE, Y. Iniciação à Fonética e à Fonologia. 3a ed. rev. Rio de Janeiro: Jorge Zahar Editor, 1994.

CALLOU, D.; MORAES, J. A. de. Condicionamentos sócio e geolinguísticos na realização do /R/ no português do Brasil. Revista Estudos Linguísticos e Literários, n. 17, p. 69-78, 1995. 
CALLOU, D.; MORAES, J. A.; LEITE, Y. Variação e diferenciação dialetal: a pronúncia do /R/ no português do Brasil. In: KOCH, I. V. (org) Gramática do Português Falado. $2^{a}$ ed. Campinas, SP: Editora da Unicamp, 2002, p. 463-489.

CHAMBERS, J. K.; TRUDGILL, P. Dialectology. New York: Cambridge University Press, 1982.

CARDOSO, S. A. Dialetologia. In: MOLLICA, M. C.; FERRAREZI JR, C. Sociolinguística, sociolinguísticas. São Paulo: Editora Contexto, 2016.

GUY, G. R.; ZILLES, A. Sociolinguística quantitativa: instrumental de análise. São Paulo: Parábola Editorial, 2007.

HORA, D. da; MONARETTO, V. N. de O. Enfraquecimento e apagamento dos róticos. In: HORA, D. da; COLLISCHONN, G. (Org.) Teoria linguística: fonologia e outros temas. João Pessoa: EDUFPB, 2003.

LEAL, E. G. Os róticos no VARSUL: uma generalização de dados. ReVEL, edição especial n. 13, 2016.

MALMBERG, B. A fonética: no mundo dos sons da linguagem. Lisboa: Livros do Brasil, 1954.

MONARETTO, V. N. de O. Um reestudo da vibrante: análise variacionista e fonológica. 1997. 213f. Tese (Doutorado em Letras). PUCRS, Porto Alegre, 1997.

MONARETTO, V. N. de O. Descrição da vibrante no sul do Brasil. In: BISOL, L.; COLLISCHONN, G. (Orgs). Português do sul do Brasil. Porto Alegre: EDIPURCS, 2009, p. 141-151.

NASCIMENTO, T. A. M. Os róticos na fala de três municípios fluminenses: Petrópolis, Itaperuna e Parati. 2009. 128f. Dissertação (Mestrado em Letras). Universidade Federal do Rio de Janeiro, Rio de Janeiro, 2009.

OLIVEIRA, M. B. de. Manutenção e apagamento do (r) final de vocábulo na fala de Itaituba. 2001. 98f. Dissertação (Mestrado em Letras). Universidade Federal do Pará, Belém, 2001.

PAIVA, M. da C. de. A variável gênero/sexo. In: MOLLICA, C.; BRAGA, M. L. (Org.) Introdução à sociolingüística: o tratamento da variação. 3. ed., 1. reimp. São Paulo: Contexto, 2008.

SCHAEFFER, S. C. B. Descrição fonética e fonológica do pomerano falado no Espírito Santo. Dissertação (Mestrado em Linguística). Faculdade de Letras, Universidade Federal do Espírito Santo, 2012.

SEARA, I. C. Fonética e fonologia do Português Brasileiro. Florianópolis: LLV/CCE/UFSC, 2008.

SILVA, T. C. Fonética e fonologia do português: roteiro de estudos e guia de exercícios. 6 ed. São Paulo: Contexto, 2002.

SKEETE, N. A. O uso variável da vibrante na cidade de João Pessoa. Revista Graphos, v. 2, n. 1, p. 77-96, 1997. 
VIEIRA, S. O estudo dos róticos no Estado do Espírito Santo. 2017. 188 f. Tese (Doutorado em Estudos de Língua) - Instituto de Letras, Universidade do Estado do Rio de Janeiro, Rio de Janeiro, 2017.

VOTRE, S. Variação fonológica no Rio de Janeiro. 1978. 206f. Tese (Doutorado em Linguística). Pontífica Universidade Católica do Rio de Janeiro, Rio de Janeiro, 1978.

Nota do editor:

Artigo submetido para avaliação em: 30 de setembro de 2020.

Aprovado em sistema duplo cego em: 12 de março de 2021. 